Research Article

\title{
Social Interaction and Stock Market Participation: Evidence from China
}

\author{
Zhifeng Liu, ${ }^{1}$ Tingting Zhang, ${ }^{1}$ and Xiaoguang Yang ${ }^{1,2}$ \\ ${ }^{1}$ College of Management and Economics, Tianjin University, Tianjin 300072, China \\ ${ }^{2}$ Academy of Mathematics and Systems Science, Chinese Academy of Sciences, Beijing 100190, China
}

Correspondence should be addressed to Zhifeng Liu; zhfliu@126.com

Received 27 December 2013; Accepted 23 January 2014; Published 27 February 2014

Academic Editor: Fenghua Wen

Copyright (C) 2014 Zhifeng Liu et al. This is an open access article distributed under the Creative Commons Attribution License, which permits unrestricted use, distribution, and reproduction in any medium, provided the original work is properly cited.

Current research on the impact of social interaction on the stock market participation only involves the traditional way of social interaction, and this paper further investigates the modern social interaction effects on the stock market participation and its activeness. The sample containing 150 Chinese counties is selected, and we apply grouping analysis and linear regression to conclude that social interaction has positive influence on the stock market participation and its activeness. Both traditional and modern social interaction ways affect the stock market participation and its activeness to the similar extent, so modern social interaction is of the same importance. Controlling for the respondents' age, wealth, and education level, the above conclusion still holds.

\section{Introduction}

After 35 years of the reform and opening-up policy, China's economic level is progressing continuously and national income is growing very fast, and more and more people begin to participate in the stock market. At the end of the year 2012, as reported by China Securities Depository and Clearing Corporation Limited (CSDC), there are about 170 million of private equity accounts in China, and the effective account number is about 140 million, while the new account number in whole year of 2012 is about 5562 thousand. That is to say, in China, about ninety percent of the people do not hold stocks, which is called "stock market participation puzzle."

What are the factors that affect the people's behavior of stock market participation? Previous research about this problem has obtained some conclusions [1-3]. Generally, there are three kinds of factors: first, the effects come from personal and family background. Lusardi uses data from American stock market as research sample and finds that investors' age, gender, and race can influence the stock market participation [4]. Love and Smith find that single investor's health does not impact on his or her portfolio selection, while, for married investors, health has a weak effect [5]. Almenberg and Gender find that female's participation in the stock market is significantly less than male's [6]. Bogan proves that the gender of the offspring will affect parents' investment decision. The second kind of factors is about wealth and income [7]. Bertaut and Starr, Moskowita and Vissing all find that wealth has a positive effect on equity participation $[8,9]$. Bonte and Filipiak discover that, in India stock market, investors' income and social class have a significant influence on the stock market participation [10]. The third kind of factors is about investors' education level, cognitive ability, and risk attitude. For example, Grinblatt, Keloharju, and Linnainmaa find that the IQ has monotonous positive correlation with the stock market participation [11]. Klapper et al. find that the financial literacy of the Russsian investors is positively relatedto the stock market participation [12].

The above investigations of various factors affecting stock market participation are mainly about individual factors and do not involve the interactive behavior between individuals. We know that the financial market is complex [13], and interpersonal interaction in or out of the market, such as word of mouth, can produce and transfer information, which is one of the important factors that may influence people's decision 
making [14-17]. Similarly, when stock information transferred by communication, social interaction may affect people's behavior of the stock market participation.

Some scholars have studied this problem, and they all find that people who have social interaction with friends or neighbors can increase the possibility of stock market participation [18]. Massa and Simonov find that social interaction can significantly affect investors' stock selection especially that among college graduate students takes an important role in stock market participation [19]. Brown et al. find that the word-of-mouth communication between community neighborhoods will significantly affect the stock market participation, and if the neighbors who hold stocks increase by $10 \%$, then the investors' possibility of buying this kind of stock will increase by $4 \%$ [20]. Dierkes et al. also find a similar conclusion in German market: if the average participation rate of individual's friends increases by $10 \%$, then the investor's probability of holding risk assets will increase by $4 \%$ [21]. Other scholars further explain how social interaction affects the stock market participation. For example, Hong et al. think that social interaction can influence the stock market participation by at least two ways [22]: the learning behavior though interaction and the pleasure gained from interaction. Their empirical results also prove that the individuals who take part in social interaction will be more likely to hold stocks. Chang believes that social behavior will obviously produce the herding behavior, which has an impact on the stock market participation [23].

Chinese scholars do not put enough attention on this problem yet, and their research mainly depends on some regional data. Li uses the survey data of residents in Guangdong province in 2004 as research sample and builds a linear probit model to analysis of the correlation between social interaction and stock market participation [24]. His result shows that social interaction and the trust will promote the stock market participation, and he also finds that social interaction will significantly encourage residents who have lower level of education to participate in stock market. Li uses Chinese investor behavior survey data of 12 cities in 2008 as research sample and finds social interaction generally contribute to the investors' stock participation [25]. He also thinks that the reason why social interaction plays the positive role of individual investment is mainly because of the endogenous regulatory mechanisms of social interaction. Zhou et al. use a 2008 survey data which come from Peking University and Sun Yat-Sen University and find that, in developed regions, such as Beijing, Shanghai, and Guangzhou, social interaction plays a prominent role in promoting individual's stock market participation [26].

However, there are at least three aspects of defects in the above researches. First, the domestic and foreign scholars have only studied how the traditional ways of social interaction influence the stock market participation, and they do not consider that the modern social interaction may also affect stock market participation. With the development of human society and the progress of science and technology, there are more and more ways existed to interact with people. Compared with traditional face-to-face interaction, modern ways of social interaction tend to use the advanced technology, such as telephone. These modern ways of social interaction have not only changed the traditional pattern of interaction between people but also offer the channel to transfer the information which related to stock market, which further affect the people's behavior of stock market participation. Therefore, when we study on the influence factors of people's stock market participation, we should consider the influence from modern social interaction. Second, in the above literature, the ways of people's stock market participation are very simple. People involved in the stock market have different risk preferences [27] and also have different ways of stock market participation. Therefore, investigating the activeness of stock market participation is a good way to deepen the study of stock market participation. Third, in the case of China, the research samples of the existing research literature are regional data, not including the nationwide data, which may cause the bias in the data selection. So, it is necessary to adopt a more comprehensive sample.

In order to solve the above problems, this paper adopts the broader data as the research sample to examine how Chinese residents' social interaction affects their stock market participation behavior. In this paper, the measures of this behavior not only involve the common measure of stock market participation but also introduce a new measure which can depict the activeness of participation, which can help us to understand the stock market participation behavior better.

The rest of the paper is organized as follows. Section 2 introduces the selection and dispose of the sample. Section 3 includes model specification and empirical analysis. The last section is conclusion.

\section{The Data}

The data we used come from China Health and Retirement Longitudinal Study (CHALRS) in 2011. This survey comprises China's 150 counties, 450 villages, 10 thousand families, and 17 thousand residents, and the questionnaire design references from U.S. health and retirement survey (HRS), the United Kingdom aged tracking survey (ELSA), the European health, old age, and retirement survey (SHARE), and other methods, so the acquired survey data is quite reliable.

This paper selects two different measures of stock market participation. First of all, according to the usual practice in the existing literature [22], this paper uses "Have you held any stocks in the past year in your name, excluding the equity or stock of your work unit?" as a measure for investors' stock market participation, notated as $Y_{1}$. If the respondents hold stocks in the past year, $Y_{1}=1$; otherwise, $Y_{1}=0$. Secondly, unlike previous literatures, this paper also introduces another index to measure investors' activeness of stock market participation. In stock market, as we know, there are some investors holding stocks for a long time but not trading frequently. On the other hand, there are also some investors who are likely to trade frequently. In particular, in China's stock market, the trading frequency is very high, and the high turnover rate becomes one of the important features of the Chinese stock market. Because of the analysis above, we use "Have you done Stock investment in the last month?" to measure 
the respondents' activeness of stock market participation, notated as $Y_{2}$. If the respondents trade their stock in the past month, $Y_{2}=1$; otherwise, $Y_{2}=0$. In order to distinguish these two measures, we define $Y_{1}$ as stock market participation and $Y_{2}$ as activeness of stock market participation. The former one is the measure of the stock market participation which is consistent with the previous literatures; the latter one can describe the investors' activeness of stock market participation. Then, we can study the behavior of investors' stock market participation in different angles.

To introduce our measures of social interaction, we have compared the measures in ancient literatures and focused on more related questions in the survey, which makes our measures more credible. This paper selects the following 11 variables, and each variable with its corresponding question is as follows: $X_{1}$ : interacted with friends; $X_{2}$ : played ma-jong, played chess, played cards, or went to community club; $X_{3}$ : provided help to family, friends, or neighbors who do not live with you and who did not pay you for the help; $X_{4}$ : went to a sport, social, or other kind of club; $X_{5}$ : took part in a community-related organization; $X_{6}$ : done voluntary or charity work; $X_{7}$ : cared for a sick or disabled adult who does not live with you and who did not pay you for the help; $X_{8}$ : attended an educational or training course; $X_{9}$ : does your residence have a telephone connection? $X_{10}$ : does your residence have broad-band internet connection? $X_{11}$ : did you use the internet during the last month? Among them, $X_{1}-X_{8}$ and $X_{11}$ represent the behavior during the last monthwhether respondents have these behaviors in the nearest month when he/she fills in the questionnaire. $X_{9}$ and $X_{10}$ are state variables; if the respondents conform to the situation described by $X_{i}, i=1,2, \ldots, 11$, then $X_{i}=1$; otherwise, $X_{i}=$ 0 . Carefully analyzing these 11 variables, we can find that the independent variables $X_{1}-X_{8}$ mainly represent people's traditional ways of social interaction, and the variables $X_{9}-X_{11}$ can represent people's modern ways of social interaction. So this paper considers both ways of the traditional and modern social interaction and studies how they impact the stock market participation behavior.

This paper also uses the controlled variables in our research $[4,22,28]$. Based on the CHALRS questionnaire in 2011, we select age, education level, and wealth as control variables. Because of the urban-rural dual structure in China, we also consider the respondents' state of registered permanent residence (RPR), "residence" as the controlled variable. The age variable refers to the respondents' age when he/she fills this questionnaire. There are 11 education levels: (1) no formal education (illiterate); (2) did not finish primary school but capable of reading and/or writing; (3) Sishu/home school; (4) elementary school; (5) middle school; (6) high school; (7) vocational school; (8) two-/three-year College/Associate degree; (9) four-year College/Bachelor's degree; (10) Master's degree; (11) Doctoral degree/Ph.D. Each level is assigned for the number " $1-11$ " in turn, and the higher the number is, the higher education level the respondent has. The wealth variable in this paper is composed of several items, including personal cash holdings, personal savings, personal bonds holdings, personal stocks holdings, and personal funds holding. For residence variable, considering China's national conditions and the requirements of this study, we simplify the answers to the original questionnaire: if the respondent's answer is "(1) Agricultural RPR," then the residence variable equals 1; if the respondent's answer comes from "(2) Nonagricultural RPR, (3) Unified RPR, or (4) Do not have RPR," then the residence variables equal 0 . Finally we eliminate the outliers and missing value and acquire a sample including 15803 questionnaires. The means and correlations of these variables are shown in Table 1.

As seen in Table 1 , the mean of $X_{1}$ equals 0.3528 , indicating that there are about $35 \%$ of the people who have visited friends in the past month, which is higher than the other means of proxy variables of traditional social interaction. In the subsequent empirical analysis, we will take $X_{1}$ as the main proxy indicator of traditional social interaction. Among the three proxy variables of modern social interaction, the mean of $X_{9}$ is the highest, which equals 0.49 , so we take $X_{9}$ as the main proxy indicator of modern social interaction in the subsequent analysis.

In Table 1, we also find the positive correlations between all of eleven measures of social interaction, indicating that all of these variables in this paper are consistent. All the values of the correlation between the dependent and independent variables are positive and most of them are statistically significant, and we also can get the preliminary conclusion: there is a positive correlation between social interaction and stock participation.

\section{Empirical Results}

3.1. Grouping Analysis of the Stock Market Participation. Some scholars, such as Hong et al. and Dierkes et al., have proved that people's social interaction has a significant influence on their stock market participation $[21,22]$, and it seems that there is a similar influence in China, based on the preliminary analysis about Table 1 . In this section, we make a simple test to have a further study through grouping analysis. There are two groups of respondents: "social group" and "non-social group." In the social group, the respondents usually take part in the social interaction, while, in the nonsocial group, they have less social interaction than in the social group. The results of the grouping analysis are shown in Table 2.

As shown in Table 2, the average value of $Y_{1}$ is higher in each social group than in corresponding nonsocial group, and most of these differences are statistically significant, no matter how grouping the respondents, suggesting that there is a higher participation rate in social group than in nonsocial group and both the traditional and modern ways of social interaction will affect the stock market participation. When grouping by the main proxy variable of traditional social interaction, $X_{1}$, the change of the mean of $Y_{1}$ is very significant, suggesting that respondents who often interact with friends are more likely to participate in the stock market. In addition, when grouping by the main proxy variable of modern social interaction, $X_{9}$, the change of the mean of $Y_{1}$ is also significant, indicating that respondents who install a telephone in the home are more likely to hold stocks. Note 


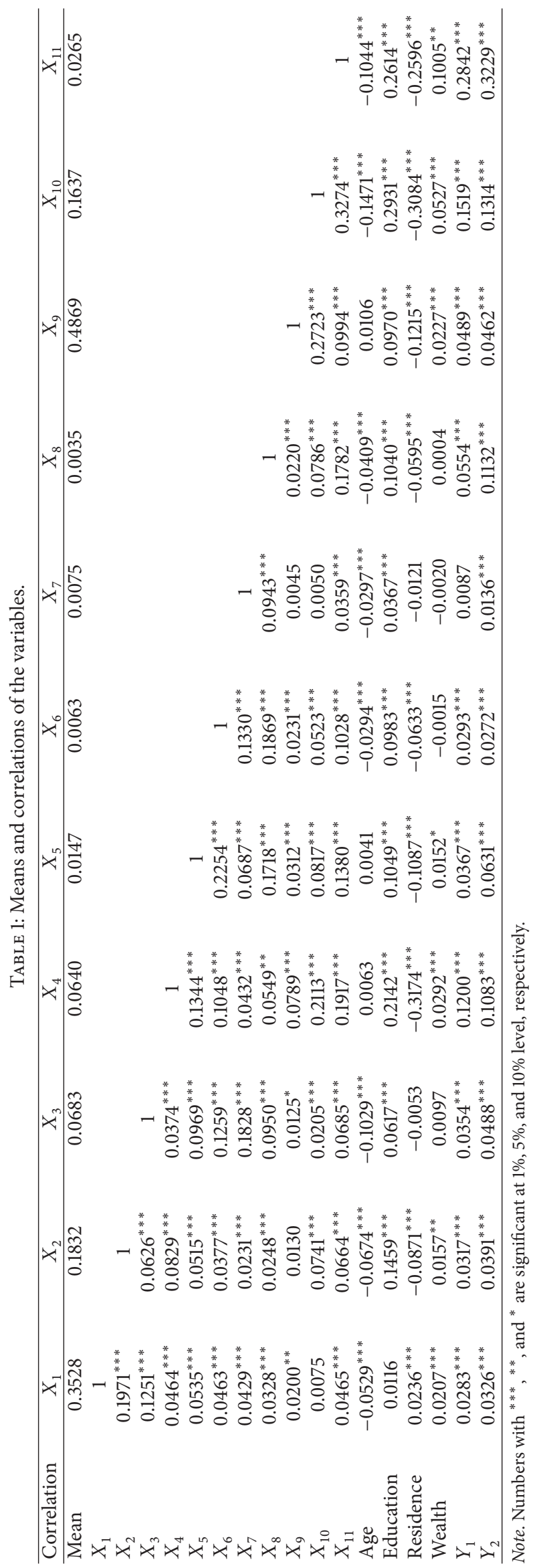


TABLE 2: Stock market participation rates in different groups.

\begin{tabular}{lccc}
\hline & Nonsocial group & Social group & Mean test \\
\hline \multicolumn{4}{c}{ Traditional social interaction } \\
$X_{1}$ & 0.0061 & 0.0113 & $-3.5535^{* * *}$ \\
$X_{2}$ & 0.0066 & 0.0138 & $-3.9716^{* * *}$ \\
$X_{3}$ & 0.0071 & 0.0195 & $-4.4405^{* * *}$ \\
$X_{4}$ & 0.0051 & 0.0485 & $-15.1545^{* * *}$ \\
$X_{5}$ & 0.0075 & 0.0343 & $-4.5901^{* * *}$ \\
$X_{6}$ & 0.0077 & 0.0404 & $-3.6625^{* * *}$ \\
$X_{7}$ & 0.0078 & 0.0168 & -1.0997 \\
$X_{8}$ & 0.0076 & 0.0893 & $-6.8964^{* * *}$ \\
\hline \multicolumn{4}{c}{ Modern social interaction } \\
$X_{9}$ & 0.0037 & 0.0124 & $-6.1509^{* * *}$ \\
$X_{10}$ & 0.0020 & 0.0383 & $-19.3076^{* * *}$ \\
$X_{11}$ & 0.0038 & 0.1603 & $-37.1654^{* * *}$ \\
\hline
\end{tabular}

Note. The mean of $Y_{1}$ equals 0.0079 . The numbers with ${ }^{* * *},{ }^{* *}$, and ${ }^{*}$ are significant at $1 \%, 5 \%$, and $10 \%$ level, respectively.

that we can conclude the same result when grouping by the proxy variables $X_{10}$ and $X_{11}$, and it seems that the online activities can significantly increase the stock market participation rate. But there may be an endogeneity problem, and, that is to say, because of the need of investing in the market, investors are more likely to install broadband and connect to the Internet. Anyway, we believe that there is not a serious endogeneity problem when using the variable $X_{9}$, that is because, in China, investors' trading mainly depends on the Internet not the telephone. So, in the subsequent analysis, we will take the variable $X_{9}$ as the main measure of the modern ways of social interaction.

We also examine how traditional and modern social interaction influence the activeness of stock market participation through the grouping analysis, and all the results are shown in Table 3. We can find that the average value of $Y_{2}$ in the social group is significantly higher than in nonsocial group, even grouping by different proxy variables of social interaction, which further proves that both traditional and modern social interaction not only influence the stock market participation but also affect the participation's activeness.

\subsection{Traditional and Modern Social Interactions' Influences on} the Stock Market Participation. The above preliminary analysis shows that people's social interaction can influence stock market participation. In order to put a further study, this paper builds a simple linear model to examine how traditional and modern social interaction influence the stock market participation. (Similar to Hong et al. study in 2004, we only give the results from a linear model. But we also have used the probit and logit models to redo all of the tests in our paper and find that the results are nearly consistent with the linear model.) The model is shown as below:

$$
\begin{aligned}
Y_{1}= & c_{i}+a_{i} \cdot X_{i}+b_{i} \cdot \text { Age } \\
& +d_{i} \cdot \text { Education }+e_{i} \cdot \text { Residence }+f_{i} \cdot \text { Wealth }+\mu_{i},
\end{aligned}
$$

TABLE 3: The activeness of stock market participation in different groups.

\begin{tabular}{lccc}
\hline & Nonsocial group & Social group & Mean test \\
\hline \multicolumn{4}{c}{ Traditional social interaction } \\
$X_{1}$ & 0.0036 & 0.0088 & $-4.2248^{* * *}$ \\
$X_{2}$ & 0.0041 & 0.0114 & $-4.8238^{* * *}$ \\
$X_{3}$ & 0.0044 & 0.0195 & $-6.4936^{* * *}$ \\
$X_{4}$ & 0.0034 & 0.0356 & $13.5532^{* * *}$ \\
$X_{5}$ & 0.0048 & 0.0472 & $8.7514^{* * *}$ \\
$X_{6}$ & 0.0052 & 0.0404 & $-4.7464^{* * *}$ \\
$X_{7}$ & 0.0056 & 0.0168 & $-1.6916^{*}$ \\
$X_{8}$ & 0.0049 & 0.1607 & $15.9479^{* * *}$ \\
\hline \multicolumn{4}{c}{ Modern social interaction } \\
$X_{9}$ & 0.0021 & 0.0090 & $-5.8833^{* * *}$ \\
$X_{10}$ & 0.0011 & 0.0275 & $-16.8022^{* * *}$ \\
$X_{11}$ & 0.0015 & 0.1507 & $-43.2711^{* * *}$ \\
\hline Note. The mean of $Y_{2}$ equals 0.0054 . The numbers with ${ }^{* * *},{ }^{* *}$, and ${ }^{*}$ are \\
significant at 1\%, 5\%, and 10\% level, respectively.
\end{tabular}

where $i=1,2, \ldots, 11$ and age, education, residence, and wealth are controlled variables. The key coefficient $a_{i}$ represents the degree of the social interaction's influence on stock market participation.

The regression results are shown in Table 4. First, all of the key coefficients, $a_{i}$, are positive and most of all are significant under $10 \%$ significant level, suggesting that there is a positive correlation between social activities and stock holding, which could be interpreted such that people may be influenced by the surrounding people when interacting with them and become more likely to invest in the stock market. In addition, we find that the coefficient of $X_{1}$, which represents the traditional way of interaction, equals 0.0047 and is significant under the level of 0.01. Meanwhile, the coefficient of $X_{9}$, which represents the modern way of interaction, equals 0.0043 and is also significant under the level of 0.01. Comparing these two coefficients, we find that there is so little difference between the influence degrees of traditional and modern social interaction on the stock market participation, which indicates that the influence of modern social interaction is equally important. Note that the coefficients of the independent variables $X_{2}$ and $X_{7}$ are not significant. This is perhaps because these activities like playing cards and taking care of the patients do not carry information about stock price.

The regression results about the controlled variables are also shown in Table 4. Most of all the coefficients, $b_{i}$, are significantly negative, suggesting that the older people are less possible to invest in stock market. All the coefficients, $d_{i}$, are significantly positive, indicating that the higher education level the respondents have, the more possible to hold stocks they will be. Learning from the significant positive coefficients of wealth, we can infer that the more wealth the respondents have, the more possible to participate in stock market they will be. These results are consistent with the previous literature. In particular, all coefficients of residence, $e_{i}$, are significantly negative, suggesting that, in China, the respondents who have the nonagricultural registered permanent residence 


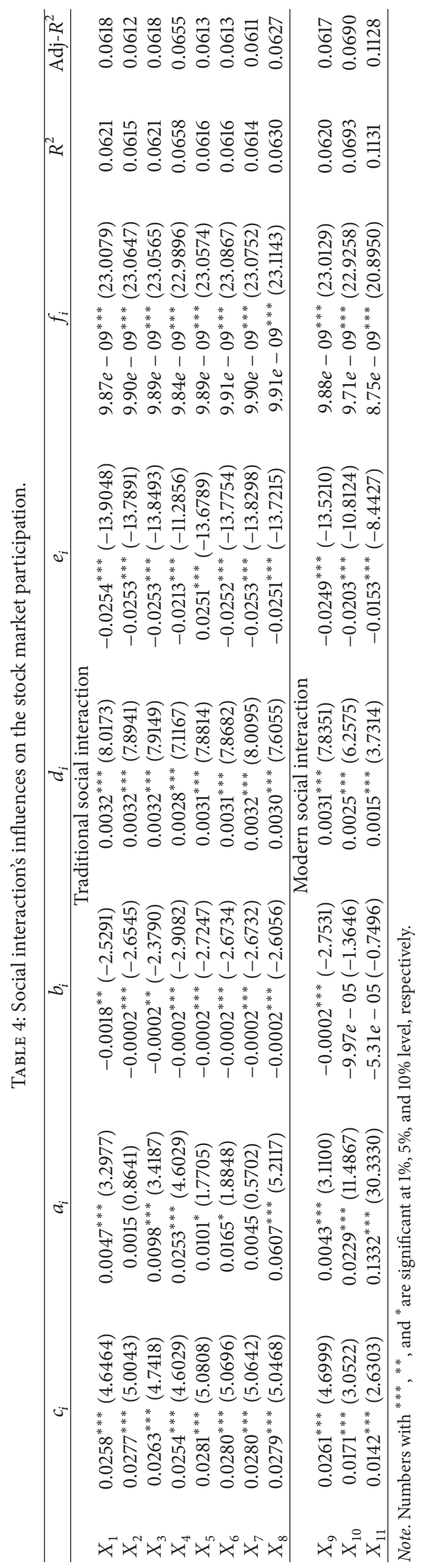




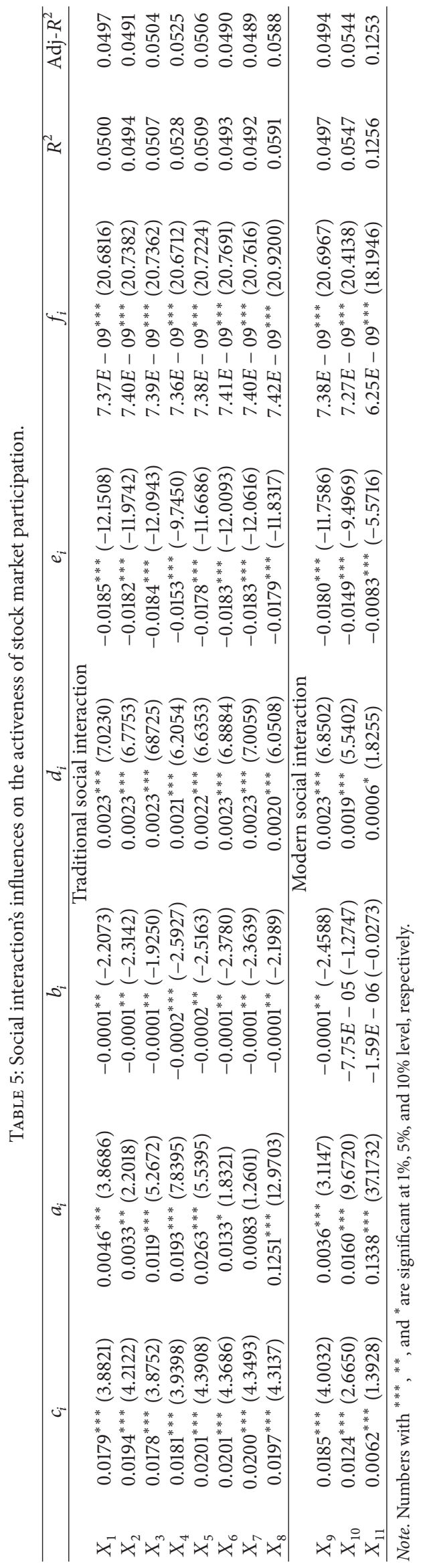


are more likely to hold stocks than the agricultural respondents. This phenomenon may be associated with China's current urban and rural duality structure.

3.3. Traditional and Modern Social Interactions' Influences on the Activeness of the Stock Market Participation. Further, we propose a similar model and make an empirical analysis on the dependent variable $Y_{2}$ to examine how the participants' traditional and modern ways of social interaction affect the activeness of stock market participation. The model is as follows:

$$
\begin{aligned}
Y_{2}= & c_{i}+a_{i} \cdot X_{i}+b_{i} \cdot \text { Age }+d_{i} \cdot \text { Education } \\
& +e_{i} \cdot \text { Residence }+f_{i} \cdot \text { Wealth }+\mu_{i}
\end{aligned}
$$

where $i=1,2, \ldots, 11$ and age, education, residence, and wealth are controlled variables. The results are shown in Table 5.

As shown in Table 5, all of the key coefficients, $a_{i}$, are positive and most of all are significant under the level of 0.1 , which shows that the participants' social interaction will have a positive influence on the activeness of stock market participation. The corresponding coefficients of traditional and modern social interactions are equal to 0.0046 and 0.0036 , respectively, and both are significant under the $1 \%$ significant level, which means that the people who prefer visiting and communicating others by telephone are more inclined to change the stock holding frequently. Different from the results in Table 4, the coefficient of $X_{2}$ in Table 5, $a_{2}$, becomes significant, which suggests that social activities like playing cards have no influence on stock holding but have a significant effect on the activeness of stock market participation. It seems to be contradictory, but it may be because there are different effects on long-term and short-term holders of stock. Anyway, the results in Tables 4 and 5 are nearly consistent, which further proves that there is a close correlation between social interaction and the stock market participation.

\section{Conclusions}

With the rapid economic development in china, the number of households that have installed the fixed telephone or the broadband network is increasing, and more and more people gradually begin to use these modern ways to communicate with the outside world. At the same time, more and more people participate in stock market and hope to gain the greatest possible benefits through their own efforts. The existing literature has proved that traditional social interaction has a positive effect on the stock market participation, and this paper further studies how modern social interaction influences the stock market participation by using the survey data from CHALRS. After controlling the participants' age, level of education, wealth, and registered permanent residence, a simple linear model is presented and the main conclusions are as follows.

First, social people who usually interact with others are more likely to hold stocks, and both traditional and modern social interactions will have an almost equal impact on stock market participation. That is to say, the modern social interaction has become an important factor affecting the behavior of stock market participation. Second, social interaction not only affects the stock market participation but also affects the activeness of the stock market participation. In other words, social people not only are more likely to hold stocks but also are more likely to trade stocks frequently. Third, different ways of social interaction will have different effects on the stock market participation and its activeness, which suggests that interacting with different people will result in different effects.

As we have mentioned, surfing the internet is another important modern way of social interaction, which may also have an effect on the stock market participation. But,in this paper, because of a potential endogeneity problem, the Internet-related conclusions are not reliable enough, which is to be solved as our future work. In addition, a variety of correlations in financial market usually are time varying [29], so, in the future work, a time-varying correlation between social interaction and stock market participation is also worth to be considered.

\section{Conflict of Interests}

The authors declare that there is no conflict of interests regarding the publication of this paper.

\section{Acknowledgments}

The research is supported by National Science Foundation of China (NSFC) (nos. 70933003 and 71131007) and the 973 Program (2010CB731405).

\section{References}

[1] L. Guiso and T. Jappelli, "Awareness and stock market participation," Review of Finance, vol. 9, no. 4, pp. 537-567, 2005.

[2] Y. Bonaparte and A. Kumar, "Political activism, information costs, and stock market participation," Journal of Financial Economics, vol. 107, no. 3, pp. 760-786, 2013.

[3] J. Favilukis, "Inequality, stock market participation, and the equity premium," Journal of Financial Economics, vol. 107, no. 3, pp. 740-759, 2013.

[4] A. Lusardi, Financial Literacy: An Essential Tool For InFormed Consumer Choice? National Bureau of Economic Research, 2008.

[5] D. A. Love and P. A. Smith, "Does health affect portfolio choice?” Health Economics, vol. 19, no. 12, pp. 1441-1460, 2010.

[6] J. Almenberg and D. A. Gender, "Stock market participation and financial literacy," SSE/EFI Working Paper Series 737, 2012.

[7] V. L. Bogan, "Household investment decisions and offspring gender: parental accounting," Applied Economics, vol. 45, no. 31, pp. 4393-4406, 2013.

[8] C. C. Bertaut and M. Starr, Household Portfolios in the United States, 2000.

[9] T. J. Moskowitz and A. Vissing-Jorgensen, "The returns to entrepreneurial investment: a private equity premium puzzle?" National Bureau of Economic Research, 2002. 
[10] W. Bonte and U. Filipiak, "Financial Literacy and Social Networks Empirical Evidence from the Indian Caste System," 2010.

[11] M. Grinblatt, M. Keloharju, and J. Linnainmaa, "IQ and stock market participation," The Journal of Finance, vol. 66, no. 6, pp. 2121-2164, 2011.

[12] L. Klapper, A. Lusardi, and G. A. Panos, "Financial literacy and its consequences: Evidence from Russia during the financial crisis," Journal of Banking \& Finance, vol. 37, no. 10, pp. 39043923, 2013.

[13] F. Wen, Z. Li, C. Xie et al., "Study on the fractal and chaotic features of the Shanghai composite index," Fractals, vol. 20, no. 02, pp. 133-140, 2012.

[14] G. Ellison and D. Fudenberg, "Word-of-mouth communication and social learning," The Quarterly Journal of Economics, vol. 110, no. 1, pp. 93-125, 1995.

[15] A. Banerjee and D. Fudenberg, "Word-of-mouth learning," Games and Economic Behavior, vol. 46, no. 1, pp. 1-22, 2004.

[16] H. Hong, J. D. Kubik, and J. C. Stein, “Thy neighbor's portfolio: word-of-mouth effects in the holdings and trades of money managers," The Journal of Finance, vol. 60, no. 6, pp. 2801-2824, 2005.

[17] Y. Liu, J. Meng, W. You et al., "Word-of-mouth Communication, Observational learning, and Stock Market Participation,” 2013.

[18] D. Simon and R. Heimer, "Facebook finance: How social interaction propagates active investing," 2012.

[19] M. Massa and A. Simonov, "History versus geography: the role of college interaction in portfolio choice and stock market prices," 2004.

[20] J. R. Brown, C. Z. Ivković, P. A. Smith, and S. Weisbenner, "Neighbors matter: causal community effects and stock market participation," The Journal of Finance, vol. 63, no. 3, pp. 1509-1531, 2008.

[21] M. Dierkes, A. Klos, and T. Langer, "Do my friends influence my investment behavior? Evidence from a representative sample of the German population," 2009.

[22] H. Hong, J. D. Kubik, and J. C. Stein, "Social interaction and stock-market participation,” The Journal of Finance, vol. 59, no. 1, pp. 137-163, 2004.

[23] S. Chang, "Herd behavior, bubbles and social interactions in financial markets," Studies in Nonlinear Dynamics and Econometrics, vol. 18, no. 1, pp. 89-101, 2013.

[24] T. Li, "Social interaction, trust and stock market participation," Economic Research Journal, vol. 1, pp. 34-45, 2006 (Chinese).

[25] T. Li, "Social interaction and investment choice," Economic Research Journal, no. 8, pp. 45-57, 2006 (Chinese).

[26] M. Zhou, L. Sun, and Y. Liu, "Social interaction, relative wealth concern and stock market participation," Journal of Financial Research, no. 2, pp. 172-184, 2011 (Chinese).

[27] F. Wen and X. Yang, "Skewness of return distribution and coefficient of risk premium," Journal of Systems Science \& Complexity, vol. 22, no. 3, pp. 360-371, 2009.

[28] W. Bonte and U. Filipiak, "Financial investments, information flows, and caste affiliation: empirical evidence from India," Schumpeter Discussion Papers, 2011.

[29] F. Wen and Z. Liu, "A copula-based correlation measure and its application in chinese stock market," International Journal of Information Technology and Decision Making, vol. 8, no. 4, pp. 787-801, 2009. 


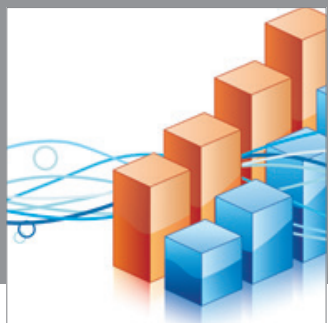

Advances in

Operations Research

mansans

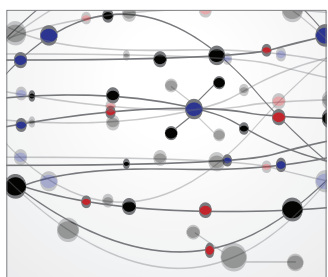

The Scientific World Journal
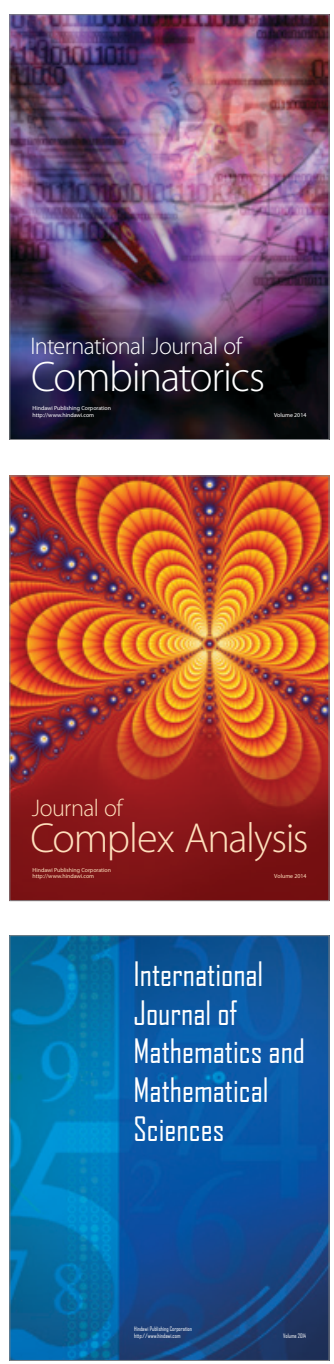
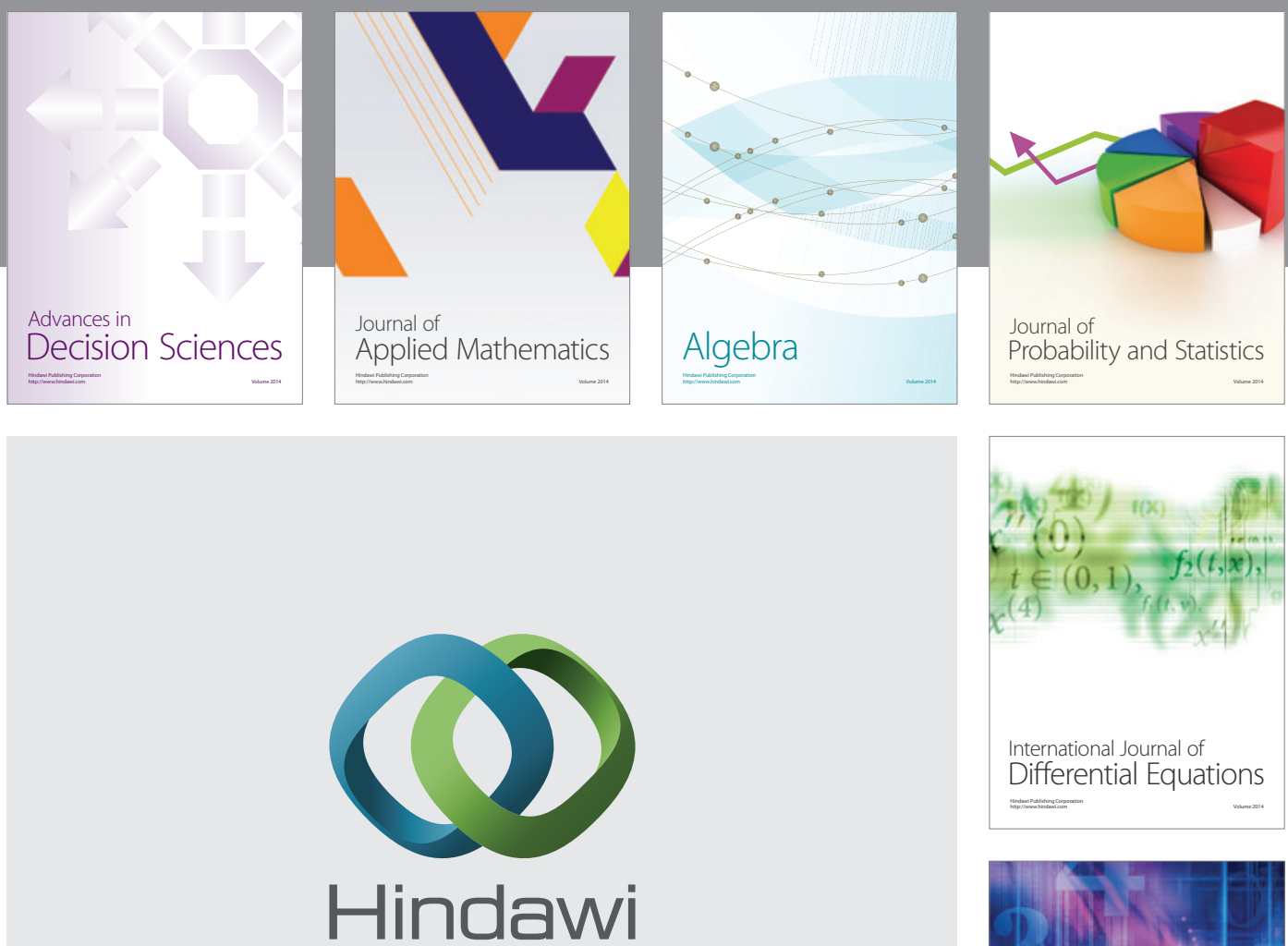

Submit your manuscripts at http://www.hindawi.com
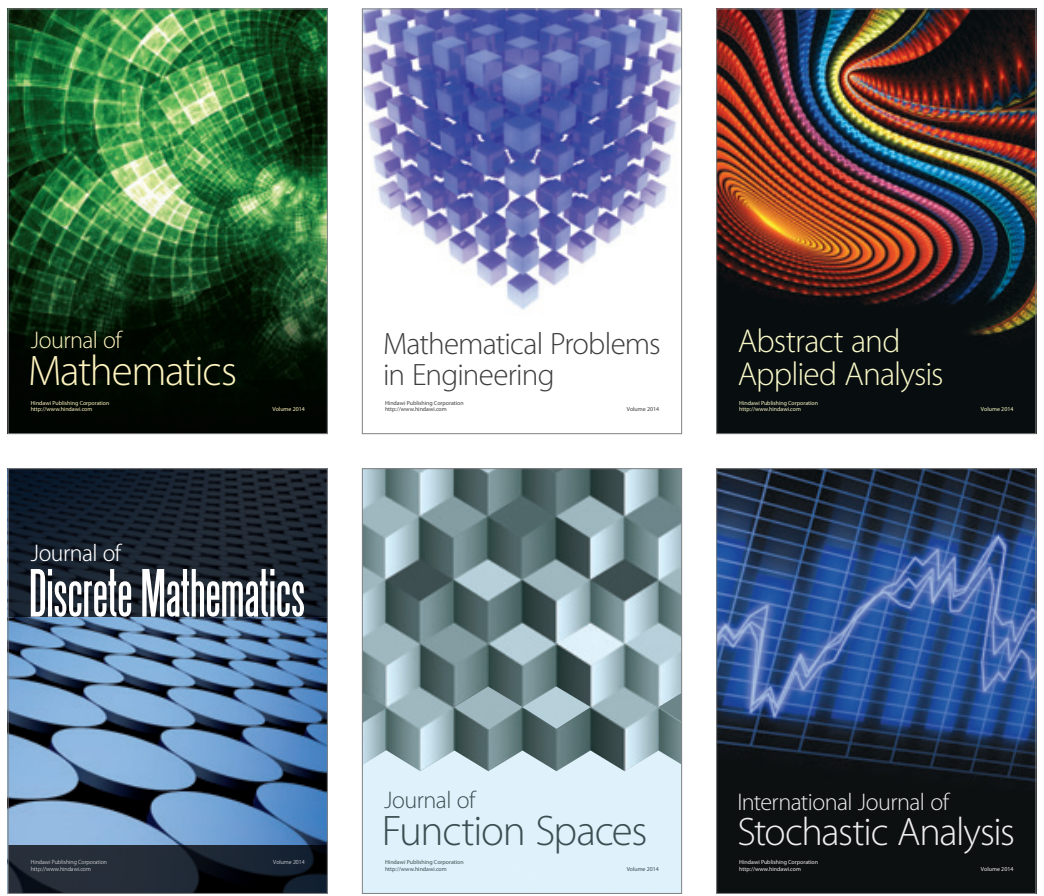

Journal of

Function Spaces

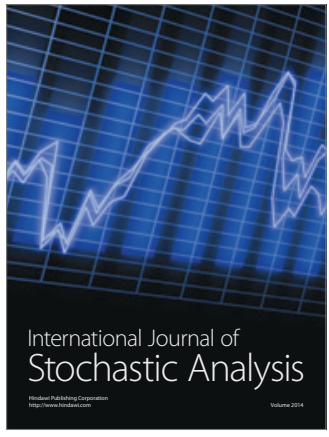

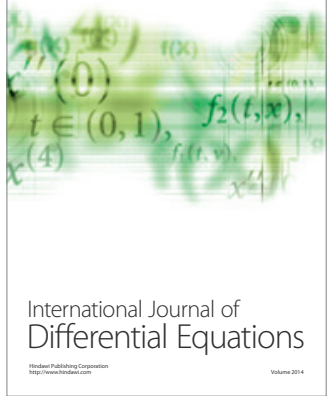
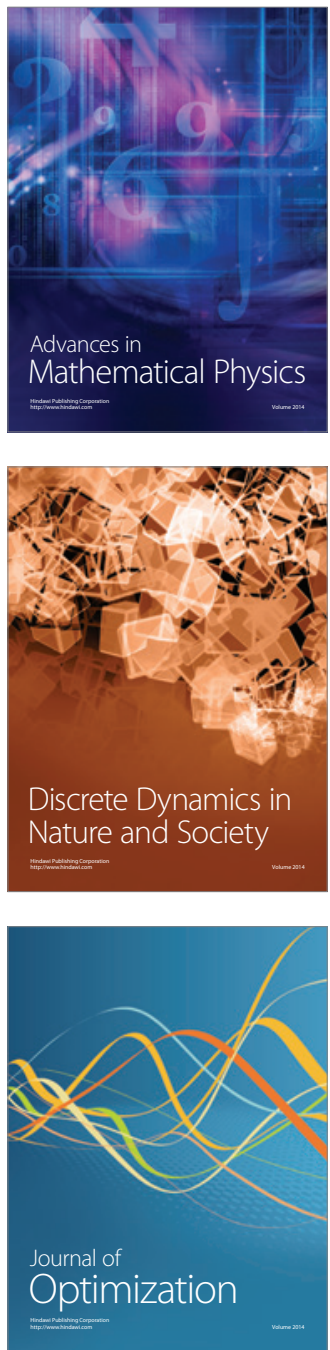